\title{
Evaluation of the effects of native minerals on the organic matter of Aleksinac oil shale based on the composition of free and bound bitumens
}

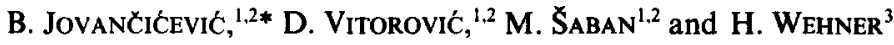 \\ 'Department of Chemistry, University of Belgrade, P.O. Box 550, 11001 Belgrade, Yugoslavia, 2Institute \\ of Chemistry, Technology and Metallurgy, 11000 Belgrade, Yugoslavia and ${ }^{3}$ Federal Institute for \\ Geosciences and Natural Resources, P.O. Box 510153, D-3000 Hannover 51, Germany
}

(Received 10 June 1991; accepted in revised form 12 November 1991)

\begin{abstract}
In order to evaluate the adsorption and catalytic effects of indigenous carbonates and silicates on the organic matter of Aleksinac oil shale, the free and the bound bitumens were isolated and analyzed by organic geochemical methods.

The differences in the gross compositions indicated an adsorption effect on both the carbonates and silicates in the examined oil shale.

The maturation parameters, based on $n$-alkanes and isoprenoid alkanes pristane and phytane, indicated that bitumen 3 was of the highest, and bitumen 1 of the lowest, apparent maturity.

The silicates were shown to have had a thermocatalytic effect on the organic matter of this sediment. Clay minerals had a catalytic effect primarily on sterane aromatization, rearrangement of steranes into diasteranes and their $(20 R) \rightarrow(20 S)$ isomerization.

All evidence obtained by analysis of steranes and aromatic steroids suggested that the differences in bitumen compositions should be explained by the effect of clay minerals rather than by variations in the origin of the precursor biomass.
\end{abstract}

Key words -Aleksinac oil shale, indigenous carbonates and silicates, catalytic effect, free bitumen, bound bitumen, biomarker parameters, maturation

\section{INTRODUCTION}

Mineral components in sedimentary rocks may have a significant influence on the alteration of organic matter. This is mainly a result of adsorption and/or catalytic effects, the two most important types of interaction between inorganic and organic materials in sediments (Tannenbaum et al., 1986). The intensity of these interactions was recently illustrated by RockEval analysis of sedimentary rocks which showed the bound bitumen to appear in the $S_{2}$ rather than the $S_{1}$ peak (Wilhelms et al., 1991).

In order to understand the composition of different forms of organic matter in the geosphere it is necessary, and of great importance, to know the extent of adsorption and catalytic effects of individual mineral components. Due to differences in the adsorption capacity of various minerals, the primary migration of the bitumen depends largely on the mineral composition of the source rock (Sajgo et al., 1983). Therefore, but also because of the selectivity of different mineral constituents towards diverse organic compounds in the bitumen, the composition and type of oil may depend on the type of minerals in the source rocks (Huizinga et al., 1987a). Moreover, the bitumen and petroleum compositions have to be related to the mineral constituents of the source

*To whom all correspondence should be addressed. rock, due to variations in the thermocatalytic characteristics of individual minerals, primarily clays (Huizinga et al., 1987b).

Since particular minerals were found to influence the composition of bitumen in the source rocks, and the composition of oil in the reservoir rocks as well, knowledge of the degree of interactions between mineral and organic components in the sediments is of great importance in oil-to-oil and oil-to-source rock correlations. On the other hand, bearing in mind the thermocatalytic characteristics of individual clay minerals, one should not neglect the effect of minerals on the yield of gaseous and liquid products in the pyrolysis of oil shales (Jeong and Patzer, 1983).

In order to evaluate the adsorption and catalytic effects of indigenous carbonates and silicates on the organic matter of Aleksinac oil shale, the free bitumen (bitumen 1) and the bound bitumens (bitumens 2 and 3) were isolated and analyzed. Presuming that the bound bitumens 2 and 3, compared to the free bitumen 1 , are more strongly influenced by the mineral components, the question was whether the differences in the group compositions, as well as abundances and distributions of $\boldsymbol{n}$-alkanes, isoprenoid alkanes, polycyclic alkanes of sterane type and mono- and triaromatic steroids, in bitumens 1,2 and 3 of this sediment, can be correlated with the effects of individual mineral constituents. 


\section{EXPERIMENTAL}

The oil shale sample originated from the Aleksinac oil shale deposit (Yugoslavia), a freshwater lake sediment of Upper Oligocene-Lower Miocene age. A sample of this shale ( $>50 \mathrm{~kg}$ ), which involved numerous sedimentary cycles, was separated from a large quantity of the rock prepared for industrial pyrolysis experiments. The sample was powdered in a semi-industrial ball mill. The sample contained $24.9 \%$ organic matter, the atomic $\mathrm{H} / \mathrm{C}-\mathrm{O} / \mathrm{C}$ ratios being 1.48 and 0.23 , respectively. $\mathrm{X}$-ray analysis of the raw shale revealed the presence of the following mineral constituents: quartz, calcite, pyrite, plagioclase, illite, kaolinite and montmorillonite (Vučelić et al., 1992). Bitumens 1, 2 and 3 were isolated according to the scheme shown in Fig. 1.

The free bitumen (bitumen 1) was obtained by Soxhlet extraction of the powdered dry oil shale sample. Bitumen 2 was extracted after removal of carbonates by treatment with $3 \mathbf{M}$ hydrochloric acid, and bitumen 3 after the elimination of silicates by treatment of the $\mathrm{HCl}$-concentrate with a mixture of concentrated hydrochloric and hydrofluoric acids (1:1).

The bitumens were analyzed according to the scheme given in Fig. 2.
The $n$-alkanes and the isoprenoid alkanes pristane and phytane, in the form of urea adducts, and the saturated hydrocarbon fractions, were analyzed by gas chromatography (GC) using a Varian 3300 gas chromatograph (FID) fitted with a capillary column coated with BP-1 and using hydrogen as carrier gas at $1 \mathrm{~cm}^{3} / \mathrm{min}$ flow rate

Polycyclic alkanes of sterane type (urea nonadducts) and mono- and triaromatic steroids (aromatic fractions) were analyzed by gas chromatography-mass spectrometry (GC-MS) using the single ion monitoring (SIM) method. The steranes were identified from $m / z 217$, monoaromatic steroids from $m / z 253$ and triaromatic steroids from $m / z 231$ fragmentograms. A Hewlett-Packard 5840 A GC was used fitted with a capillary column coated with SE-54 and using helium as carrier gas (flow rate $1 \mathrm{~cm}^{3} / \mathrm{min}$ ), coupled to a Hewlett-Packard $5985 \mathrm{MS}$ operated at $70 \mathrm{eV}$.

\section{RESULTS AND DISCUSSION}

\section{Gross compositions}

The gross compositions of the free bitumen 1 and the bound bitumens 2 and 3 are shown in the form of a triangular diagram (Fig. 3).

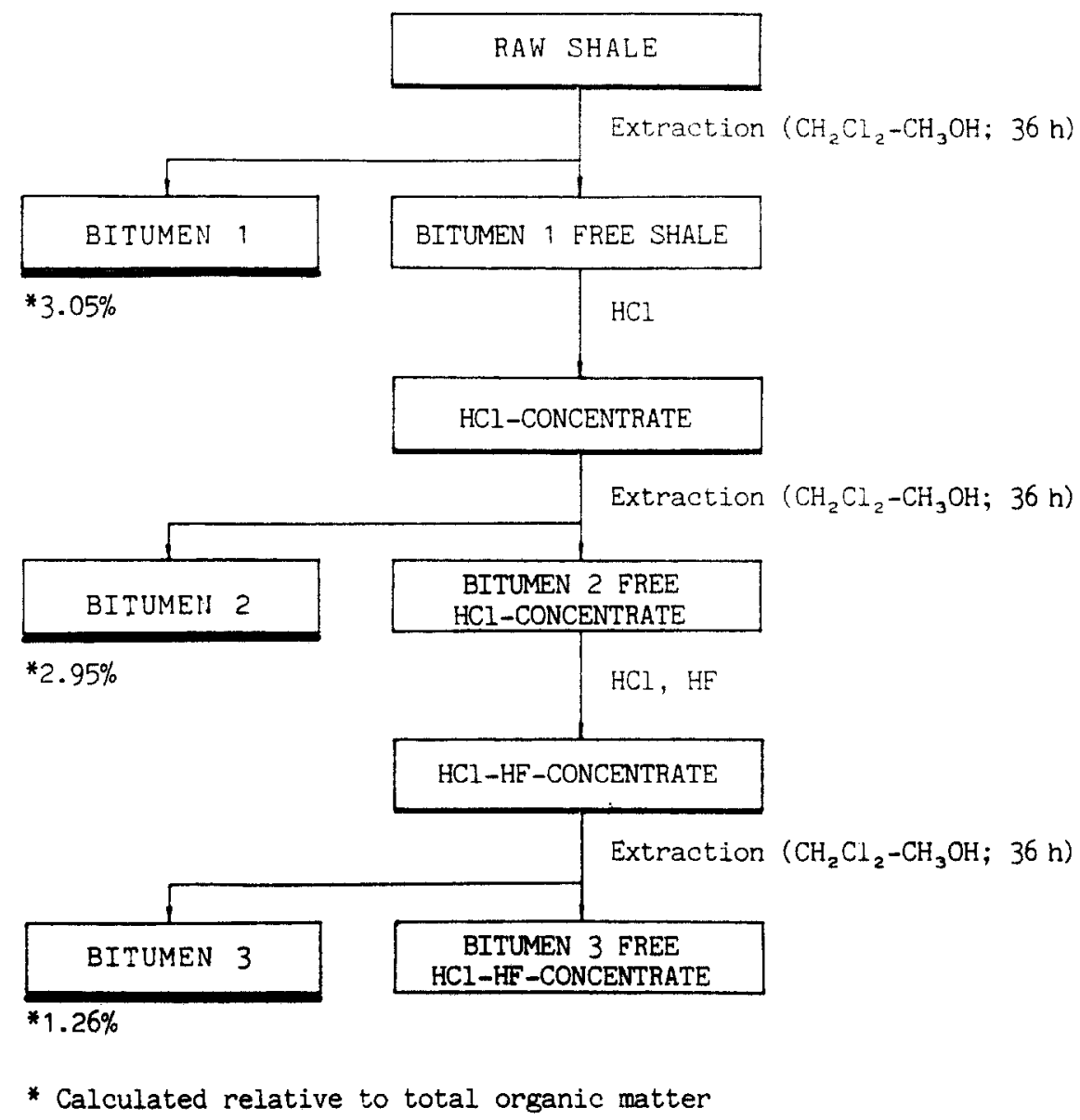

Fig. 1. Isolation of bitumens 1,2 and 3 from Aleksinac oil shale. 


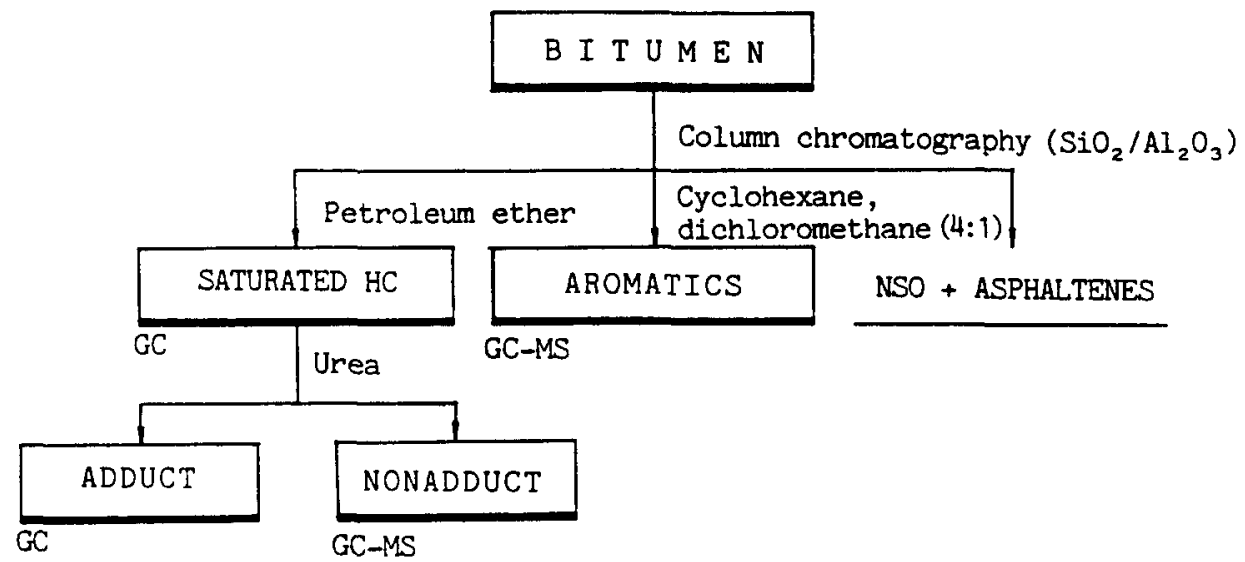

Fig. 2. Analysis of bitumens 1-3. The content of NSO-compounds and asphaltenes was determined by difference, from the initial weight of the sample and the sum of saturated hydrocarbons and aromatics contents $(\mathrm{GC}=$ gas chromatographic analysis, GC-MS = gas chromatographic-mass spectrometric analysis).

The content of saturated hydrocarbons in bitumen 1 was much higher than in bitumens 2 and $3(27.7 \%$ relative to 5.7 and $6.2 \%$, respectively; Fig. 3). The content of aromatic hydrocarbons in bitumen 1 was also higher than in bitumens 2 and 3 (7.8 vs 4.6 and $4.8 \%$, respectively; Fig. 3). The differences in the gross compositions of the bitumens may be due only to adsorption effects of the carbonates and silicates in the oil shale.

The adsorption characteristics of the minerals in sedimentary rocks, exhibited mostly through adsorption of heavier, polar components, i.e. the NSOcompounds and asphaltenes, are most strongly pronounced with the clay minerals (Tannenbaum et al., 1986). However, surprisingly, the observed similar gross compositions of bitumens 2 and 3 did not suggest that the silicate minerals in the tested sample had a higher adsorption ability than the carbonates.

\section{n-Alkanes and isoprenoid alkanes}

Gas chromatograms of urea adducts ( $n$-alkanes) are shown in Fig. 4. Parameters calculated on the basis of gas chromatograms of total saturated hydrocarbons, as well as gas chromatograms of $n$-alkanes shown in Fig. 4, are given in Table 1.

The differences in the distributions of $n$-alkanes and pristane and phytane (Fig. 4 and parameters 2-6 in Table 1) cannot be related exclusively to the adsorption characteristics of carbonate and silicate minerals.

The calculated parameters may be source, maturation, and even migration parameters (Waples, 1985; Leythaeuser and Schwarzkopf, 1986). However, the $n$-alkane maxima as well as the CPI values $\left(\mathrm{C}_{27}\right.$ and CPI $>1$ in all samples, Table 1) suggested that most probably bitumens 1, 2 and 3 may have had a similar, terrestrial origin. On the other hand, different values

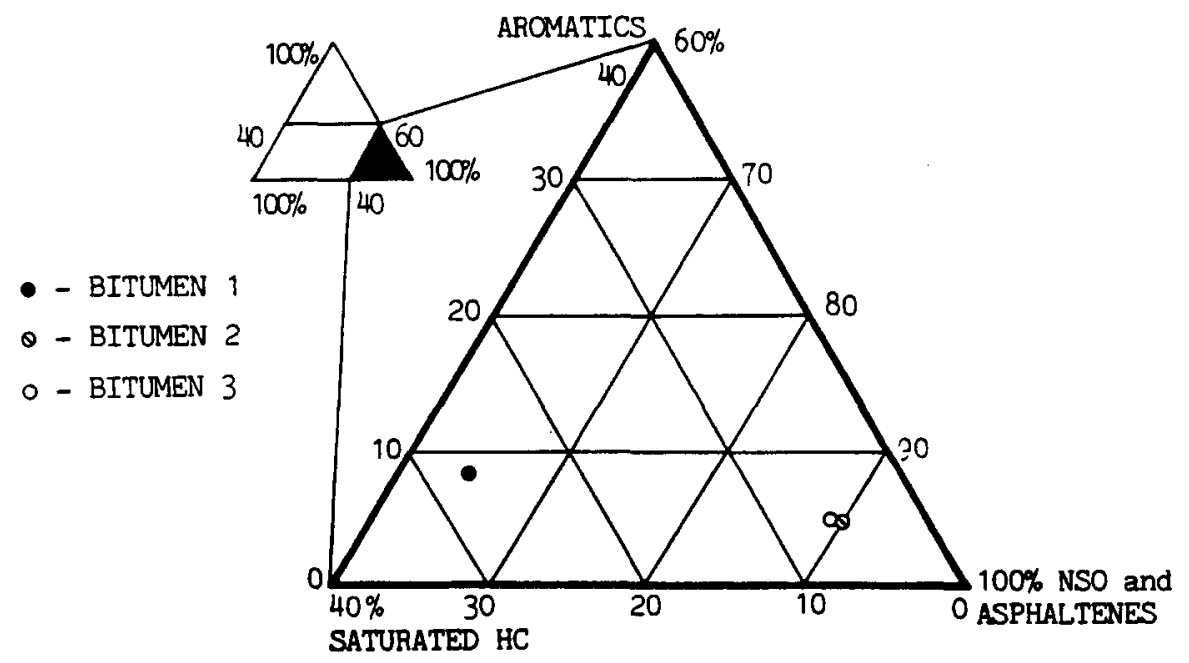

Fig. 3. Gross composition of examined bitumens. 


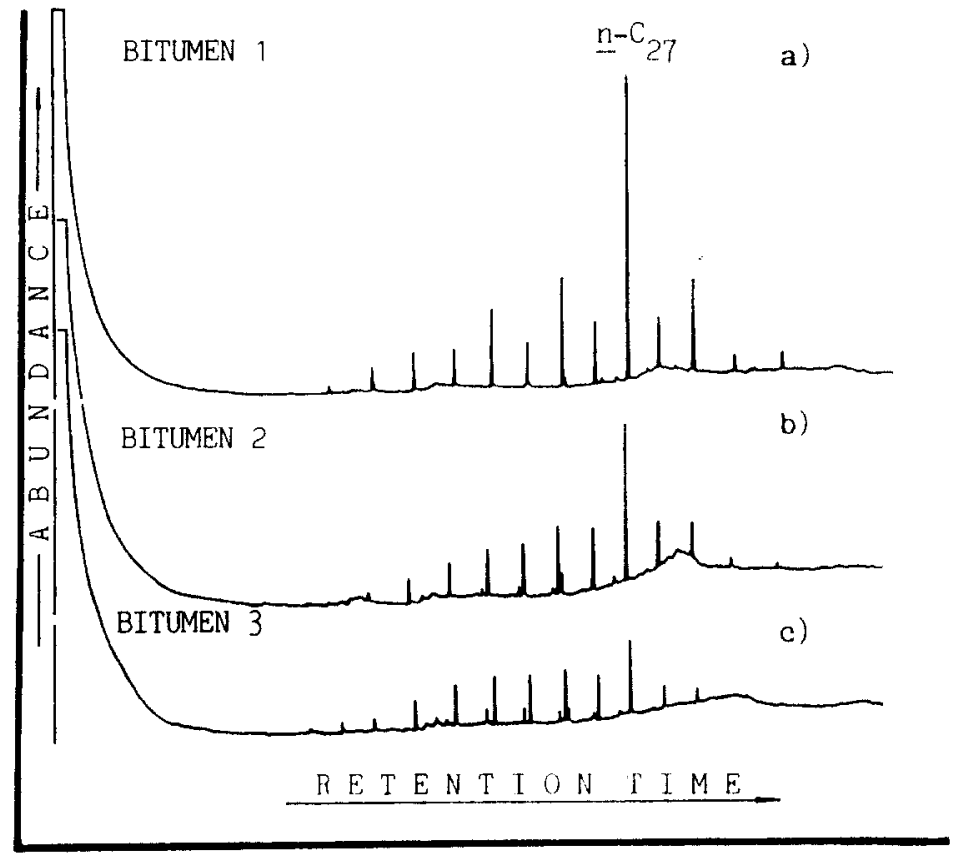

Fig. 4. Gas chromatograms of $n$-alkanes (urea adduct) of bitumen 1 (a), bitumen 2 (b) and bitumen 3 (c).

of parameters $2-6$ in Table 1 can neither be due to migration since the analyzed bitumens originated from the same oil shale sample.

Parameters 2-6 from Table 1, when considered as maturity parameters indicate, without exception, bitumen 1 to be of the lowest and bitumen 3 of the highest apparent maturity. In all three samples $n-\mathrm{C}_{27}$ is found to be the most abundant $n$-alkane, but its relative proportion is decreasing from bitumen 1 to bitumen 3. The CPI is also decreasing from bitumen 1 to bitumen 3. The same is true for the $\mathrm{Pr} / \mathrm{Phyt}$, $\operatorname{Pr} / n-\mathrm{C}_{17}$ and $\mathrm{Phyt} / n-\mathrm{C}_{18}$ ratios. Since all three bitumens originated from the same oil shale sample, they were exposed during their geological history to the same temperatures and pressures. Therefore, the highest apparent maturity of bitumen 3 may only be explained by the strongest catalytic effect of clay minerals on the thermal alteration of bitumen 3 . Hence, the term apparent maturity, as used in this paper, refers to organic matter alterations caused by catalytic effects of minerals, in addition to regular maturation changes. Consequently, the somewhat higher apparent maturity of bitumen 2 , compared to bitumen 1, should be due to the catalytic effect of carbonate minerals, which would accord with some of the earlier results observed by Eglinton et al. (1986). However, the very low catalytic effect of carbonates on the thermal alteration of sedimentary organic matter has been observed many times in the past (e.g. Huizinga et al., 1987a). Therefore, the

Table 1. Parameters calculated from gas chromatograms of total saturated hydrocarbons and gas chromatograms

\begin{tabular}{|c|c|c|c|c|c|c|}
\hline \multirow[b]{2}{*}{ Sample } & \multicolumn{5}{|c|}{ of $n$-alkanes } & \multirow[b]{2}{*}{ Phyt $/ n-C_{1 x}$} \\
\hline & $\begin{array}{c}\text { Most abundant } \\
n \text {-alkane }\end{array}$ & $n-C_{27} n-C_{26}$ & ${ }^{*} \mathrm{CPI}$ & Pr/Phyl & $P_{1} n-C_{1}$ & \\
\hline Bitumen 1 & $C_{27}$ & 3.60 & 2.22 & 0.67 & 3.21 & 4.95 \\
\hline Bitumen 2 & $\mathrm{C}_{27}$ & 1.98 & 1.87 & 0.50 & 1.50 & 1.00 \\
\hline Bitumen 3 & $C_{37}$ & 1.23 & 1.07 & 0.35 & 0.33 & 0.42 \\
\hline Parameter: & 1 & 2 & 3 & 4 & 5 & 6 \\
\hline
\end{tabular}

*CPI was calculated over the whole range.

Table 2. Parameters calculated from GC-MS fragmentograms of steranes $(m / z 217)$, triaromatic steroids $(m / 2=231)$ and monoaromatic steroids $(m / z 253)$

\begin{tabular}{|c|c|c|c|c|c|}
\hline Sample & $\begin{array}{l}\mathrm{C}_{27} \beta \alpha(20 S) \text {-diast. } \\
\mathrm{C}_{27} \alpha \alpha(20 R) \text {-sterane }\end{array}$ & $\begin{array}{c}\alpha \alpha(20 S) \\
C_{2 \alpha} \frac{\alpha \alpha(20 S)+\alpha \alpha(20 R)}{}\end{array}$ & $\mathrm{C}_{29} \frac{\alpha \alpha(20 S)}{\alpha \alpha(20 S)+\alpha \alpha(20 R)}$ & $\begin{array}{l}\text { *Triaromatic } \\
\text { Monoaromatic }\end{array}$ & $\frac{C_{20}}{C_{20}+C_{28}}$ \\
\hline Bitumen 1 & 0.02 & 0.03 & 0.09 & 0.61 & 0.06 \\
\hline Bitumen 2 & 0.13 & 0.22 & 0.09 & 0.77 & 0.27 \\
\hline Bitumen 3 & 0.22 & 0.36 & 0.12 & 1.17 & 0.34 \\
\hline Parameter: & 1 & 2 & 3 & 4 & 5 \\
\hline
\end{tabular}

"The abundances of the triaromatic and monoaromatic steroids are proportional to the values given in Figs 6 and 7 . 


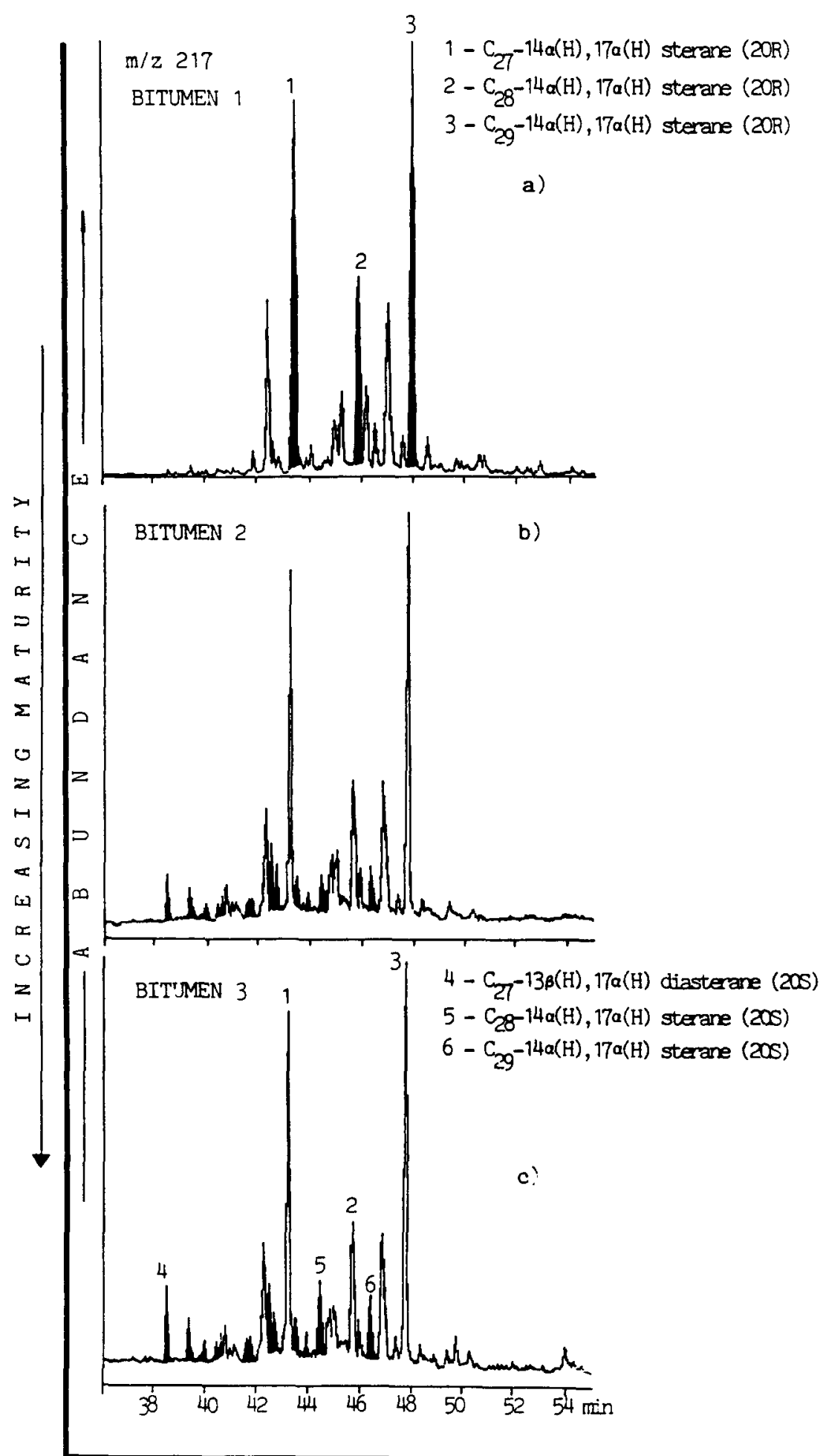

Fig. 5. Fragmentograms of $m / z 217$ (steranes) of bitumen 1 (a), bitumen 2 (b) and bitumen 3 (c). Darkened peaks on Fig. 5(a) correspond to biolipid isomers whose distribution is used for estimation of organic matter origin. Darkened peaks on (b) and (c) correspond to geolipid isomers whose concentration increases as a result of thermocatalytic effect of shale minerals on organic substance.

higher apparent maturity of bitumen 2, compared to free bitumen 1 , should tentatively also be explained as a result of the catalytic effect of clay minerals. That is, being fixed by adsorption, bitumen 2 could have been more strongly exposed to interactions with clay minerals which may be present as calcite impurities. 


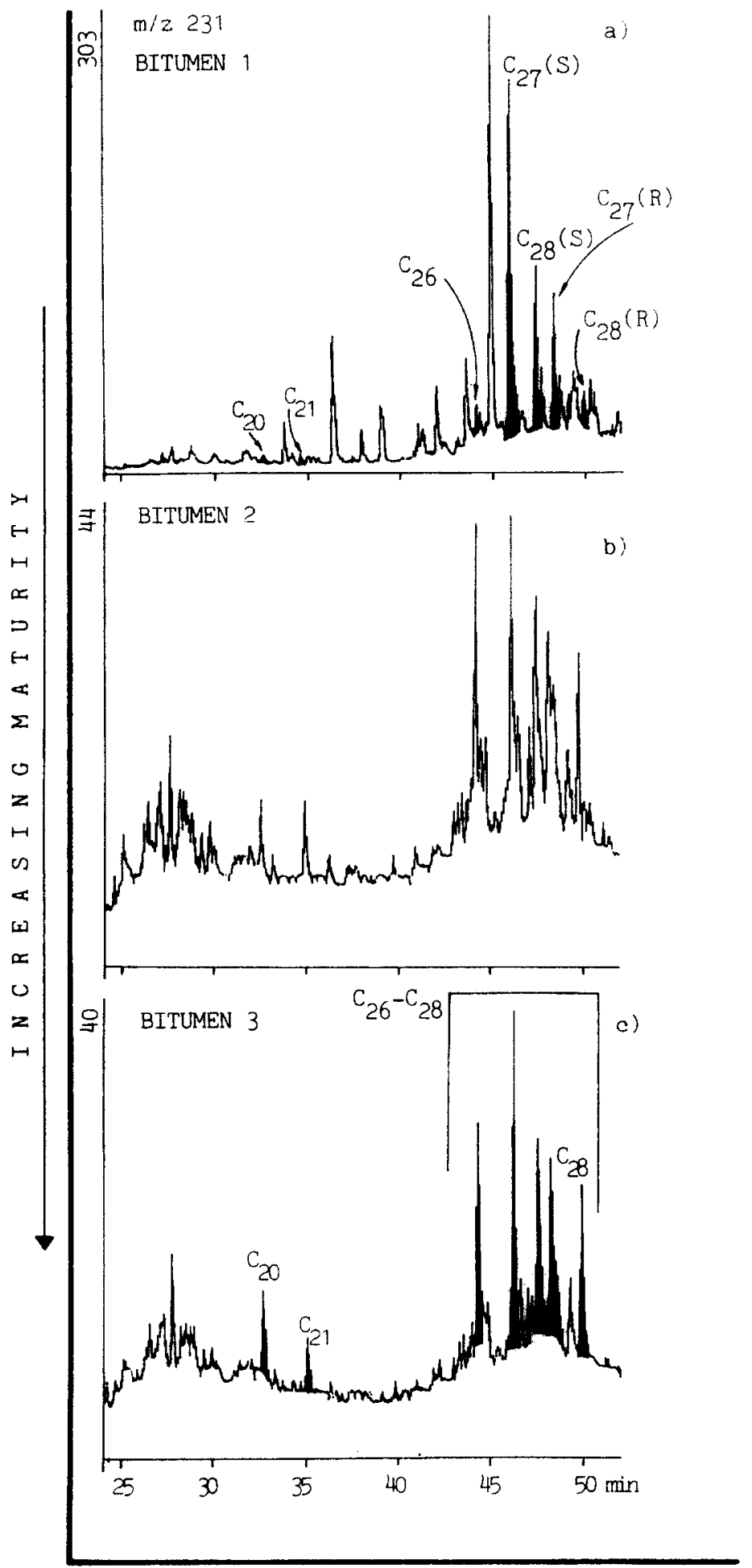

Fig. 6. Fragmentograms of $m / z 231$ (triaromatic steroids) of bitumen 1 (a), bitumen 2 (b) and bitumen 3 (c). Darkened peaks on (a) and (c) correspond to identified triaromatic steroids; differences in the ratios of lower vs higher members of the triaromatic steroid series with bitumen 1 and 3 are evidence for thermocatalytic effect of the minerals on the shale organic matter.

Bitumen 1 is at the lowest level of apparent maturation because of its restricted interaction with clay minerals.
Steranes and mono- and triaromatic steroids

Fragmentograms of $m / z 217$, which served as a basis for the identification of steranes, are given in 


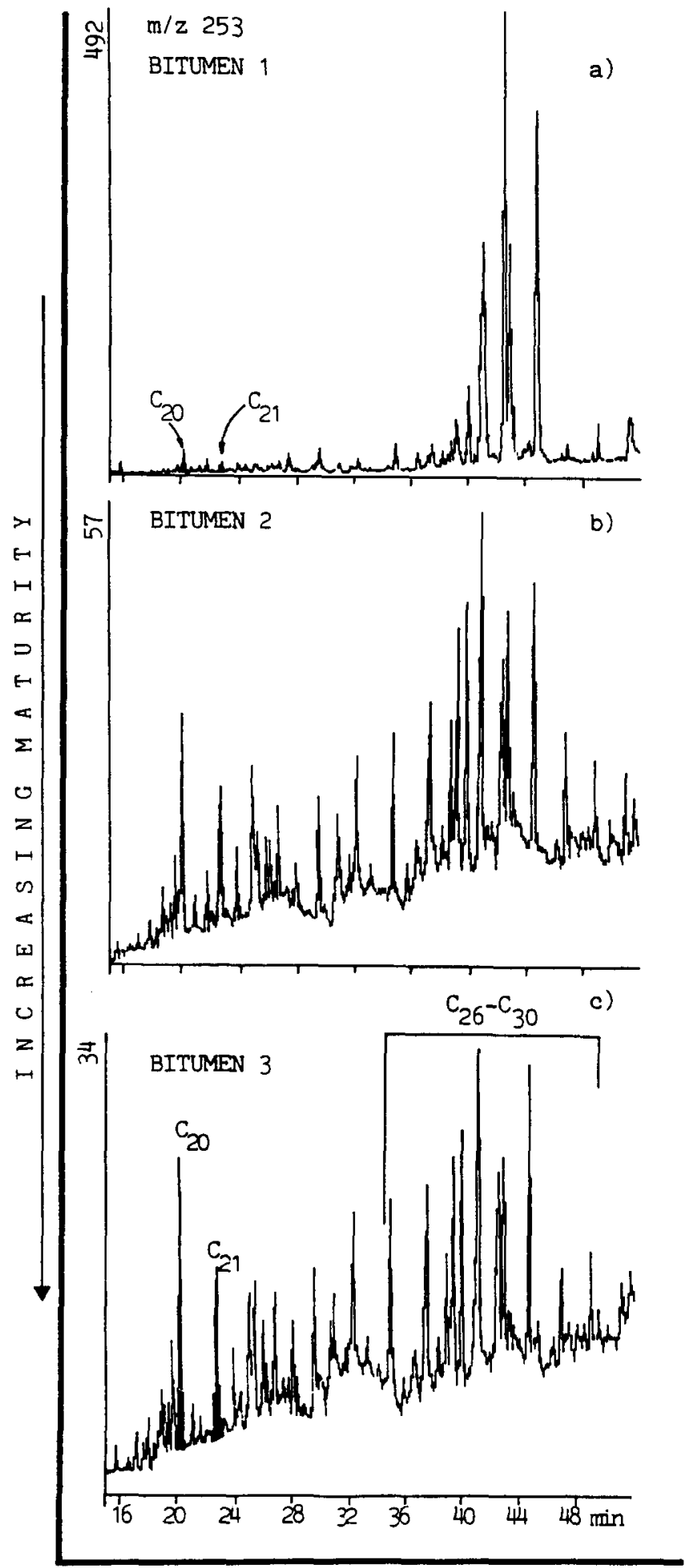

Fig. 7. Fragmentograms of $m / z 253$ (monoaromatic steroids) of bitumen 1 (a), bitumen 2 (b) and bitumen 3 (c). Darkened peaks in (a) and (c) correspond to lower molecular weight monoaromatic steroids, whose concentration increases due to thermocatalytic effects of shale minerals on the organic matter.

Fig. 5. The maturation parameters calculated from the distributions of steranes are shown in Table 2.

Almost identical distributions of regular steranes in all three samples (peaks 1,2 and 3 in Fig. 5), represented additional evidence for the same origin of the bitumens. On the other hand, the abundances and distributions of thermodynamically more stable isomers, in the first place diasteranes (Mackenzie et al., 
1980) are in full agreement with the distributions of $n$-alkanes and pristane and phytane in the alkane fractions of the same bitumens, as well as the statement on the catalytic effect of clay minerals on bitumen maturation processes. Figure 5 and Table 2 (parameter 1) show that the relative amount of diasteranes is lowest in bitumen 1 , and highest in bitumen 3 .

Parameters 2 and 3 from Table 2 indicated that clay minerals may also have affected the isomerization of steranes at C-20, because the values of $\mathrm{C}_{2 x^{*}}$ and $\mathrm{C}_{29}-\alpha \alpha(20 S) / \alpha \alpha(20 S)+\alpha \alpha(20 R)$ for bitumen 3 were higher than for bitumens 1 and $2(0.36$ vs 0.03 and 0.22 , and 0.12 vs 0.09 and 0.09 , respectively: Table 2).

Fragmentograms of $m / z 231$, identifying triaromatic steroids, and of $m / z 253$, identifying monoaromatic steroids, in bitumens 1-3, are shown in Figs 6 and 7 , respectively. Maturation parameters, calculated on the basis of abundances and distributions of these hydrocarbons, are given in Table 2

The ratios of abundances of tri- and monoaromatic steroids (parameter 4, Table 2) indicated that the aromatization of steranes in bitumen 3 , compared to bitumens 1 and 2, reached the highest degree. Furthermore, as Fig. 6 shows, and also the values of parameter 5 in Table 2, lower members of the triaromatic steroid series, e.g. the $\mathrm{C}_{20}$ and $\mathrm{C}_{21}$ members, are more abundant in bitumens 2 and 3 than in bitumen 1. The same is true for the lower members of the monoaromatic steroid series (Fig. 7). It was shown earlier (e.g. Mackenzie, 1984) that with increasing maturity of bitumens or oils, the amount of triaromatic steroids becomes higher at the expense of monoaromatic steroids, and the amount of lower members of mono- and triaromatic steroid series becomes higher at the expense of the higher members. Consequently, the differences in the abundances and distributions of mono- and triaromatic steroids, observed between bitumens 1, 2 and 3, are reliable evidence of the effects of Aleksinac oil shale mineral components, primarily clay minerals, on the thermal alteration of parts of the shale organic matter.

\section{CONCLUSIONS}

A detailed organic-geochemical analysis of the Aleksinac oil shale free bitumen 1 and bound bitumens 2 and 3 was carried out, aimed at studying the effect of indigenous minerals on the contained organic matter. Since the bound bitumen 2 (extracted after the removal of carbonates) and the bound bitumen 3 (extracted after the removal of silicates) interacted more strongly with the shale's mineral components than did the free bitumen 1 (extracted from dry shale), the differences in the compositions of bitumens 1-3 were used as a basis for the evaluation of adsorption and thermocatalytic effects of native minerals on the Aleksinac oil shale organic matter.
The differences in the gross compositions of the examined bitumens (Fig. 3), which indicated much higher contents of NSO-compounds and asphaltenes, and lower proportions of saturated hydrocarbons and aromatics, in bitumens 2 and 3, indicated an adsorption effect of both the carbonates and silicates in the oil shale.

The maturation parameters calculated from GCanalysis of $n$-alkanes and isoprenoid alkanes pristane and phytane (Fig. 4, Table 1) indicated bitumen 3 to be of highest and bitumen 1 of lowest apparent maturity. This observation suggested that silicate minerals, like illite and montmorillonite, had a thermocatalytic effect on the organic matter of this sediment. A higher apparent maturity of bitumen 2 , compared to bitumen 1 , could be due also to catalytic effects of clay minerals, supposing that bitumen 2 , by being adsorbed mostly by carbonates, was more strongly interacting with the silicates than bitumen 1 . Furthermore, the silicates interacting with bitumen 2 may eventually turn out to be impurities in the calcite.

GC-MS analysis of steranes (Fig. 5, Table 2) also supplies evidence on the thermocatalytic effects of minerals on the shale organic matter. Diasteranes are most abundant in bitumen 3, while almost absent in bitumen 1 . The clay minerals' effect on organic matter is also reflected in the $(20 S) /(20 R)$ ratios of $\mathrm{C}_{2 x}$ and $\mathrm{C}_{24}$ sterane isomers which are highest in bitumen 3 .

A further proof of the thermocatalytic effect of clay minerals was obtained from GC-MS analysis of mono- and triaromatic steroids in bitumens $1-3$ (Figs 6 and 7, Table 2). The highest ratios of tri- vs monoaromatic steroids, as well as lower members $C_{20}$ and $C_{21}$ vs higher members $C_{26}-C_{28}$ or $C_{26}-C_{31}$, with both tri- and monoaromatic steroids, respectively, in bitumen 3. clearly suggested a thermocatalytic effect of silicates on parts of the shale's organic matter.

The results obtained indicate that the clay minerals of Aleksinac oil shale have a catalytic effect on sterane aromatization, rearrangement of steranes into diasteranes and their isomerization from $(20 R)$ to $(20 S)$.

The evidence obtained from the steranes led to the conclusion that the differences in composition of biomarkers identified in free and bound Aleksinac oil shale bitumens may be explained by the changes caused by clay minerals rather than by differences in the origin of the precursor biomass.

Acknowledgements-This work was supported in part by the Research Fund of the Republic of Serbia (Yugoslavia).

\section{REFERENCES}

Eglinton T. I., Rowland S. J., Curtis C. D. and Douglas A. G. (1986) Kerogen-mineral reactions at raised temperatures in the presence of water. Org. Geochem. 10, $1041-1052$.

Huizinga J. B., Tannenbaum E. and Kaplan I. R. (1987a) The role of minerals in the thermal alteration of organic matter-III. Generation of bitumen in laboratory experiments. Org. Geochem. 11, 591-604. 
Huizinga J. B., Tannenbaum E. and Kaplan I. R. (1987b) The role of minerals in the thermal alteration of organic matter-IV. Generation of $n$-alkanes, acyclic isoprenoids, and alkanes in laboratory experiments. Geochim. Cosmochim. Acta 51, 1083-1097.

Jeong K. M. and Patzer J. F. (1983) Indigenous mineral matter effects in pyrolysis of Green River oil shale. In Geochemistry and Chemistry of Oil Shales (Edited by Miknis F. P. and McKay, J. F.) ACS Symposium Series 230, 529-542. Washington, D.C.

Leythaeuser D. and Schwarzkopf Th. (1986) The pristane/nheptadecane ratio as an indicator for recognition of hydrocarbon migration effects. Org. Geochem. 10, 191-197.

Mackenzie A. S. (1984) Application of biomarkers in petroleum geochemistry. In Advances in Petroleum Geochemistry (Edited by Brooks J. and Welte D.), Vol. 1, pp. 115-214. Academic Press, London.

Mackenzie A. S., Patience R. L., Maxwell J. R., Vandenbroucke M. and Durand B. (1980) Molecular parameters of maturation in the Toarcian shales, Paris Basin, France-I. Changes in the configurations of acyclic iso- prenoid alkanes, steranes and triterpanes. Geochim. Cos mochim. Acta 44, 1709-1721.

Sajgo Cs., Maxwell J. R. and Mackenzie A. S. (1983) Evaluation of fractionation effects during the early stages of primary migration. Org. Geochem. 5, 65-73.

Tannenbaum E., Huizinga J. B. and Kaplan I. R. (1986) Role of minerals in thermal alteration of organic matterII. A material balance. Am. Assoc. Pet. Geol. Bull. 70, 1156-1165.

Waples D. (1985) Geochemistry in Petroleum Exploration. International Human Resources Development Corp. Boston, Mass.

Wilhelms A., Larter S. R. and Leythaeuser D. (1991) Influence of bitumen-2 on Rock-Eval pyrolysis. Org. Geochem. 17, 351-354.

Vučelić D., Marković V., Vučelić V., Spiridonović D., Jovančičević B. and Vitorović D. (1992) Investigation of catalytic effects of indigenous minerals in the pyrolysis of Aleksinac oil shale organic matter. In Advances in Organic Geochemistry 1991, to be published. Presented at the 15th International Meeting on Organic Geochemistry, 16-20 September 1991, Manchester, U.K. 